Please cite as: Steele, W. (2009) 'Australian urban planners: Hybrid roles and professional dilemmas’, Urban Policy and Research, 27(2), pp. 189-203.

\title{
Australian urban planners: Hybrid roles and professional dilemmas
}

Wendy Steele, Urban Research Program, Griffith University, Brisbane, Australia.

c/- Urban and Regional Planning

Griffith School of Environment

Gold Coast campus, Griffith University

Queensland 4222, Australia

Email:w.steele@griffith.edu.au

Ph. +61-7-5552-7083

\begin{abstract}
This paper argues that a hybrid role for urban planners has emerged within the largely neoliberalised spaces of contemporary Australian governance. This new role is one that transcends previously rigid or clearly defined sectoral positions to blend public, private and community responsibilities in novel and complex ways. The first section of the paper briefly sketches the historical shifts that have led to this hitherto unseen hybrid role. The second section explores the notion of hybridity as a paradoxical professional 'third space' where dominant ideological discourses shaping planning practices such as neoliberalism can be both resisted (McGuirk, 2005) and/or reinforced (Roy, 2001). Whilst the third section of the paper shifts to ground the hybridity metaphor in real people and places through selected narratives from case-study research into the shift to performance-based planning in Queensland under the Integrated Planning Act 1997. Finally, the future of this hybrid professional role is considered within the context of an uncertain global financial climate.
\end{abstract}

\section{Introduction}

There are rather complex new partnerships being formed between private and public sectors in Australian cities that blur the distinctions ...urban research might suggest useful ways of understanding the impacts of new relationships...

(Davidson and Fincher 1998, p.193)

Since the late 1990s there have been calls for the role of the Australian urban planner to be re-assessed in response to the impact of micro-economic reform and as a means of enabling more sustainable outcomes (Davidson and Fincher, 1998; Gleeson and Low, 
2000; Sandercock, 1998). The shift from urban government to governance has seen the public sector extended (some argue contracted) to incorporate private and community sectors in policy formulation and implementation (Minnery, 2007). Deeply located within the heart of this contemporary governance framework are a growing number of private consultants who undertake core public planning responsibilities that have been outsourced by a public sector struggling to adjust to an agenda of ongoing reform. This has resulted in a new breed of hybrid planners that blend previously distinct and at times adversarial roles, in 'diverse, if typically highly uneven ways' (Healey, 2007, p.17).

This paper critically reflects on the emergence of this hybrid role carved out in Australia since the mid 1980s by a neoliberal reform agenda underpinned by the troika of competitive decentralisation, globalisation and spatial scalar multiplicity (Alsayyad, 2001; Brenner, 2004; Searle, 2005). Central to this new role is the fusion of previously separate responsibilities that are in turn shaping planning processes and outcomes in novel and complex ways (Martens, 2007). For example, a consultant may now be employed to write a local government planning scheme, assess development proposals and provide training to public sector planners, while simultaneously representing and advocating the interests of private clients. This is quite different to the notion of public-private partnerships (PPPs) where multiple but largely separate planning roles collaborate together on particular projects. By contrast the hybrid planning role is seen to be simultaneously 'public' and 'private' - a professional 'third space' that represents something other than the sum of its parts.

The emergence and impacts of this hybrid Australian planning role are the foci of this paper which is divided into four parts. First, a brief sketch of key historical shifts that have led to what I argue is the emergence of a hitherto unseen hybrid role is outlined. Next, the notion of hybridity as a paradoxical 'third space' where dominant discourses such as neoliberalism can be both resisted (McGuirk, 2005) and/or reinforced (Roy, 2001) is explored. The third part of the paper builds on the previous two sections to ground the hybridity metaphor through case-study research into the shifting role of urban planners working in Queensland under the Integrated Planning Act 1997 (IPA). Finally, the future of this hybrid professional role is considered within the context of an uncertain global financial climate.

\section{Towards hybridity: Evolving visions of the urban planner}

Since federation the role of the planner within the Australian context has tended to be a symbiotic (if often adversarial) relationship between private entrepreneurs and government bureaucrats, with periodic influence by community advocates. The early 1900 s planning role emerged largely from the colonial officer ranks of surveyors, architects and engineers to facilitate the public urban reform necessary to counter the 'detrimental effect of laissezfaire capitalism and haphazard, unchecked development on land-use, transport, housing, economic efficiency and the general well being of the metropolis and its residents' (Garnaut, 2000, p.46). This early reform agenda ushered in a government-based planning role that was seen to be distinct from the disciplines of surveying, architecture and engineering.

Within a more overt government-led context the role of the planner grew markedly in the era following the 1930s Depression and the two World Wars. Widely referred to as the 'golden age' of planning the ideological emphasis of the time was on social democracy and 
Keynesian economic strategies that positioned the state with a positive role in macroeconomic, social and environmental management. The dominance of private enterprise-led development was seen to be motivated 'more by profit making than the needs of the community' (Commonwealth Housing Commission, 1944, p.27). As public sector planning gained ascendancy newly qualified 'professional' planners were given the task of presiding over their implementation (Alexander, 2000). Drawing on inspiration from the British model of comprehensive town and country planning, state planning authorities and town planning legislation were rolled out and planning codified as a profession through the formation of the Royal Australian Planning Institute in 1951 (Wright, 2001). Yet the dominant developmentalist ethos remained unchanged but was now organised through 'a public policy framework designed and managed by experts who increasingly tried to apply scientific and economic principles to the efficient utilisation of resources' (Frawley, 1994, p.66).

By the 1960s the role of the planner was absorbed almost completely into the public bureaucracy, albeit increasingly challenged (Sandercock, 1998). The Whitlam-led Labour government came to power in 1972 on a social democratic mandate of 'redistributing the benefits of economic growth and dealing with the environmental and social costs and disadvantages of growth' (Huxley, 2000, p.132). However the dismissal of the government in 1975 marked the early beginnings of an economic rationalist agenda that emerged in response to national concerns about economic recession. The new mantra was that more freedom and less government interventionist planning was needed to pursue market-based aspirations. Others sought more politicised roles for planners that re-emphasised the ethical, distributional dimensions of the broader planning project and for planners to be more daring and less codified (Sandercock, 1998). As a result the role of the planner began a shift away from the once-dominant public sector, to occupy more specialised roles within the private sector.

Through-out the Western planning world these ideological shifts were reflected in changes to the focus of urban policy and practice. For example the rise of 'Thatcherism' in the United Kingdom during the 1980s prioritised economic efficiency and elevated market principles in planning decision-making through processes of deregulation and outsourcing (Newman and Thornley, 1996; Tewdwr-Jones and Allmendinger, 2006). Similarly in the United States the effects of the 'Reagan-Thatcher revolution supplanted Keynesianism as the dominant modus operandi. By the end of the 1980s the combined weight of the critiques against government-based planning had significantly weakened the direction and legitimacy of the public role of urban planners. In particular these critiques were selectively co-opted by a growing neo-liberal agenda around small government and minimal market intervention (Gleeson and Low, 2000). During this period the role of urban planners turned from "regulating growth to encouraging it by any and every possible means - the gamekeeper turned poacher” (Hall, 2002, p379).

The onset of the $21^{\text {st }}$ century has witnessed the further decline of earlier visions of the role public planners as a means of correcting and avoiding market failure re-focused towards a neoliberal emphasis on how best to activate the market and facilitate development (Hamnett, 2000). The drive for economic development has resulted in large-scale efforts to enhance productivity by streamlining processes through the reduction of bureaucratic regulation and red-tape (Searle, 2004). Australian planning, as Freestone (2007) observes, is no longer the sole responsibility of government as it was in the past but increasingly decentred, pulled in often contradictory directions and concerned largely with directly facilitating development through rapprochement with the private sector' (p.86). 
For Australian urban planners a new and far more complex role has opened which many planning professionals are largely ill-equipped to navigate (Powell 2006). At the urban scale, the neoliberalised agenda has emphasised: enhancing economic competitiveness by securing growth and accumulation within the context of globalisation; and transformations in the roles and responsibilities across all governance sectors including state, market and economy (McGuirk, 2007). Successive waves of policy reform initiatives have resulted in the fragmentation of public service providers accompanied by increasing levels of public goods and services sub-contracted or outsourced to the private sector (Dupont, 2003).

A professional role for planners has emerged that appears to navigate a 'third space' both in and between the public, private and third sector realms. This role could be narrated as the rise of a 'starring' private planning role amidst other public and third sector 'supporting cast' roles within an Australian urban governance context (see Minnery, 2007). A second narrative is that we are witnessing the emergence of a new type of 'shadow state' whereby the 'private sector' has taken over key functions of the state in response to state restructuring and privatisation (see Wolch, 1990). Another view, and the one adopted by this paper, is that alongside recognised sectoral roles there now co-exists a quite different hybridised role that has arisen as a result of particular political and economic contexts. The new urban planning role occupies a professional 'third space' where dominant ideological discourses shaping planning practices such as neoliberalism, have the potential to be both resisted (McGuirk, 2005) and/or reinforced (Roy, 2001).

\section{The hybridity lens: Theorising the 'Third Space'}

The notion of hybridity is a recurring and powerful leitmotif for debates around identity politics in an era defined by globalisation (Johnston et. al., 2000). It is a complex notion that alludes to interbreeding and mixing, juxtaposition and fusions - a melting pot of previously uniform understandings or typically separate entities. Importantly hybridity is understood as more than the merger of incompatible elements but rather the introduction of a 'third space' or new possibility for connecting 'originally incommensurable terms and irreconcilable realities' (AlSayyad, 2001, p.3). This 'third space' has been recognised as a site that transcends traditional modernist binaries opening up the potential for empowerment, but also disempowerment if the result is the appropriation of particular values or ideas (Massey, 1994).

The concept of hybridity has been linked largely with post colonial studies (Bhabha, 1994) and feminism (Rose, 1995). However there have been a number of attempts to theorise planning from the perspective of hybridity through the lens of hybrid role choice (Howe 1980), hybrid urbanism (AlSayyad, 2001), hybrid cultures (Sanyal, 2005), hybrid neoliberal roles (Larner, 2005; McGuirk, 2005) as well as hybridity and urban innovation (Wood and Landry 2008). In early work by Elizabeth Howe (1980) a sample of 614 planners from the Institute of American Planners working within the public sector was undertaken to establish role choices. She observed that role choice in planning contains strong ideological dimensions and developed a typology of three role choices for public sector planners:

- the technician that seeks to be a value-neutral adviser to decision-makers;

- the politician who is a value-committed activist that advocates particular policies; and

- the hybrid who is a mixture of the previous two. 
Howe's study found that the planners who identified with the hybrid role choice struggled to combine incompatible ideologies that resulted in competing 'mirror image' professional dimensions.

More recent work such as Hybrid Urbanism (AlSayyad, 2001) has significantly extended the theoretical dimensions of hybridity in urban studies to draw attention to issues of identity, space and power within a globalised era. The emphasis is on the notion of hybrid urbanism as a 'third place' within the built environment. 'Hybridity as difference' is perceived to be a means of challenging dominant norms and power structures by occupying 'borderlands' that are anchored between fixed and well-defined places - 'zones of displacement and deterritorialisation that shape the identity of the hybridised subject' (AlSayyad, 2001, p.5). The notion of hybrid planning cultures as a type of 'borderlands' is also raised by Sanyal (2005) who links the concept to the spaces created as a result of: the globalisation of production (de-industrialisation); and the ascendency of neoliberal politics and the effect of multi-pronged economic reforms to reinvent the role of government and discredit regulatory practices as a means of achieving sustainable outcomes.

These themes resonate with Australian-based geographer Pauline McGuirk (2005), however she cautions against viewing the neoliberal governance framework as an impenetrable forcefield or unified coherent project, but rather as a series of complex and overlapping strategies that offer the potential for multiple, albeit often contradictory political projects. Drawing on the writing of Wendy Larner (2005), McGuirk suggests there is a need for increased sensitivity to the hybrid nature of planning roles and practice in order to reveal the opportunities for what she describes as an 'after-neoliberalist' statebased role. This potential, she suggests, can then be used to 'enact new and different spatial and social distributional outcomes than those framed by a neoliberalised imagination' (p.62).

Not everyone is convinced of the liberatory power of hybridity however. American geographer Katharyne Mitchell (1997) coined the term 'the hype of hybridity' in reference to what she perceived to be the premature celebration of 'spaces of resistance'. Mitchell (1997) argued that hybrid roles can in fact work to reinforce hegemonic narratives and dominant capitalist discourses such as neoliberalism, rather than disturb or interrupt dominant ideologies. Hybridisation she suggests is 'produced in the context of economic as well as cultural processes that must be theorised in tandem' (Mitchell 1997, p.274). A similar theme emerges in the work of fellow American urban theorist Ananya Roy (2001) who argues that the idea of hybridity can be more seductive than subversive. In particular she calls for the need to ground hybrid spatial metaphors in real places and times to better assess the potential for new and different outcomes amidst the 'actual geographies of capital accumulation' (p.237). The next section of this paper takes up this call for a more grounded and context specific understandings of hybridity within the Australian neoliberalised urban development and policy agenda. In particular the emergence of a hybrid planning role in Queensland (Australia) is examined within the era defined by a shift to performance-based planning under the Integrated Planning Act 1997 (IPA).

\section{'Real' planning practice: Stories from planners in Queensland}

Since the late 1980s Queensland, the fastest growing state in Australia has held aspirations to be a globally competitive economic powerhouse. One of the key reforms in the push for capital accumulation has centred on the planning system amidst concerns that in a future 
where capital funds are moved around the world almost at the push of a button, the regulatory systems affecting investment and development will increasingly influence the ability to attract investment (Yearbury, 1997, p2). The shift to a more flexible, performance-based planning system under the IPA was a foundational part of this new global entrepreneurial agenda.

In the period 2007-2008 research supported by a larger ARC Linkage project was undertaken to critically assess the impact of these ideological shifts on planning practice in Queensland. Data collection methods focused on document and archival analysis as well as fifty-three in-depth interviews with diverse range of planning-related professionals in South-East Queensland.). During the interviews participants were asked to: reflect on their understanding of what constitutes 'performance-based planning'; describe and provide examples of their practice-based experiences within the performance-based agenda of the IPA; and (if applicable) contrast planning under IPA with experiences in other planning systems. To this end the interviews adopted a semi-structured research format (Patton, 1990) as a means of allowing for unanticipated themes to emerge within the context of the interview.

One recurring and intriguing theme to emerge from the data was that within the performance-based reform context of Queensland a quite different hybrid role was discernable in addition to the conventional roles for planners located predominantly within the public or private sector. Similar to the work on planning role choice in America by Howe (1980) this new role appeared to fuse previously separate or distinct roles offering both challenges and opportunities for planners seeking to enable sustainable outcomes. Unlike Howe's study however, which centred on role choice for those working solely within the public sector, in the research on the IPA this new role was occupied almost exclusively by younger IPA-generation planners located in private consultancies. For example, $\operatorname{Tim}^{1}$, a young planning consultant described his work in the following way:

Since graduating I've had a lot of different roles including preparing development assessment (DA) to lodge with council, planning scheme drafting, as well as assessing DA. I was doing work for council because they had a shortage of planners so they outsourced a lot of their development assessment work.

A similar story came from Tina, a self-described new generation 'IPA planner' who also worked as a consultant:

Now I have a big split of work that I do - a range of DA but the other aspect of the role that I do has been helping out a council with a shortage of staff and doing DA from the other side of the fence... assessing applications and writing approvals and reports for councils and stuff which is kind of hard to play the two different roles of a consultant advocating a particular development and now I'm assessing the outcomes of a particular development. But to play the two different roles has been really valuable to consider the whole process - so it has been a great learning.

The negotiation of dual sector responsibilities has created both challenges and opportunities and a role for a consultant that is simultaneously both 'insider and outsider'. This was pointed out by Mark, a young private consultant who leads a team of interdisciplinary staff:

\footnotetext{
${ }^{1}$ Pseudonyms have been used to protect the identity of all participants in the study.
} 
I used to work at council as assessment officer and now I am a consultant employed by councils as an assessor for their 'Risksmart' program. I see myself as doing planning from the outside but pretending to be inside. After all we are the same species as planners and it makes me feel like we are on the same team.

A number of inter-related themes arose from the interviews in relation to this 'hybrid' role for urban planners. These included: the impact of IPA on planner recruitment; the implications of reform agendas for the public sector and rise in private consultants; and the complexity of IPA planning roles. Each of these will be highlighted in turn.

\section{The impact of IP A on planning recruitment}

In keeping with other neoliberal agendas, planning in Queensland and the role of planners has undergone significant changes since the release of the then Goss Labour Government's state economic development policy, Queensland - Leading State (1992), which wasa central plank of the ongoing reform vision for Queensland. The key focus of the policy was an aggressive agenda of market enhancement and micro-economic reform which sought to:

- Enhance public sector efficiency through an extensive overhaul of public service delivery;

- Ensure competitive arrangements through the removal of outdated regulation

- Provide clear and consistent guidelines which allow for the development of competitive industry;

- Reject a general strategy of direct Government intervention; and

- Work with the private sector to identify and develop project opportunities and facilitate projects through to approval (Goss 1992, pp.4-5).

Building on this momentum and in keeping with other national reform agendas such as The Hilmer Report (1993), new planning legislation was introduced as a capstone planning reform initiative in the promotion of productivity, innovation and efficiency. Through the Integrated Planning Act 1997 (IPA), 21 ${ }^{\text {st }}$ century planning in Queensland was to be flexible, performance-based and responsive (Yearbury, 1998). The scale and magnitude of the changes was described in an address to the Queensland parliament as 'the State planning system being turned completely upside down' (Mackenroth, 1997, p.4546). Similarly, a discussion paper, Dynamic Planning for a Growing State (Queensland Department of Local Government and Planning, 2006), as part of a major review of IPA, reported 'a fundamental change in the culture and practice of the planning and development sector requiring stakeholders to take on new responsibilities, develop different skill sets and engage with other users of the system in different ways' (QDLGP 2006, p.13).

For Queensland planning practice a number of problems quickly surfaced: a more complex legislative framework, a lack of certainty around planning processes, and a shortage of experienced and committed planners willing to rise to the challenges of the new planning and development environment (Day, 2005; Baker et al, 2006; Fogg, 2006; Wypych et. al., 2005). Whilst planning recruitment and retention has been recognised as a national concern by the Planning Institute of Australia (Halliday, 2004), the impact in Queensland has been accentuated not only by high levels of population growth but also the introduction of IPA. As one of the study participants, Matt, a planning director with a local council highlighted:

Under IPA we have twice the number of planners doing half the applications in twice the number of time. 
The complex context surrounding the introduction of IPA and the effect on Queensland planning recruitment and retainment is clearly summarised by Terry, a planning consultant with a background in the public service:

\begin{abstract}
When IPA came in all the moons collided or aligned at the same time... You had a major change of legislation and as a result of that you had a whole bunch of senior planners pulled out [of] doing planning schemes, so we had very few planners, a new system, you had a whole bunch of state agencies who previously never employed planners suddenly thinking we need experienced planners on board and quickly [...] A whole new system came in and the experienced developers suddenly understood that they needed to employ planning firms and these planning firms started expanding but the pool of people wasn't any different to drag from in fact it was getting less. When all that lined up whenever you rang up a planner there was a different person there and the only people left were juniors acting in senior roles.
\end{abstract}

Bill, another public planner, makes the link more directly to the broader political reform agenda epitomised by documents such as the competition policies outlined by the Hilmer Report:

It is the regulatory burden carried by planning schemes that has contributed to the planning shortage. It stems back to the Hilmer report which has an awful lot to answer for because a lot of local governments took the Hilmer report to the extreme.

There is a level of irony around the regulatory burden that Bill and other participants alluded to in the interviews as the Hilmer Report centred on a policy advocating deregulation and the removal of legislative obstacles to competition (Quiggin, 1998). Paradoxically, the introduction of the new system designed to improve efficiencies in the public service was in effect, doing the reverse.

\title{
Implications of reform for the public sector and rise in private consultants
}

Whilst the impact of the reform agenda of IPA was felt across the different planning sectors, it was clear from the participant interviews that significant gains were made in the private consultancy sector at the expense of the public sector. According to Harry a local government planner:

The number of consultants has quadrupled due to [the] IPA, changing work practices and outsourcing of work from council.

The issue of the difficulties in public sector recruitment since the introduction of the IPA was a recurring theme from the planners interviewed. Participants revealed that councils overwhelmed by the increased workload under IPA were unable to resource their obligations and would thus recruit consultants to do the work. Rachel, a local government planner, observed that:

Public planners don't have the confidence or the skills. In particular, there is a lack of experience as private consultancies and developers have ripped the heart out of a lot of councils. We are still in a booming market so a lot of the experienced and good council officers have ended up in private practice so you haven't got the experienced people in council who can make a judgement call. 
This was particularly evident in relation to drafting new planning schemes which was a requirement under IPA for all Queensland councils as noted by Paul, a local government planning manager:

Drafting a planning scheme is hard and intricate. It's a project and difficult for council to employ staff for a tenure of two or less years. If you want senior people to work on this sort of stuff then you can't get them unless you offer permanent positions and even then it is hard. The reality is it was a windfall for Queensland planning consultants - IPA was an absolute windfall. Planning consultants were far quicker to position themselves to have the internal expertise to write planning schemes than local government ever did. They had more resources, expertise and capacity.

The requirements of the IPA in terms of planning scheme development and training in particular has created an employment boom for private consultants. The more the public sector has outsourced its activities the more private consultancies have thrived. Of high value within such an environment, are consultants who come with experience working within the public sector - the 'belly of the beast' (Sandercock 2005, p.??). These planners operate simultaneously as both insiders and outsiders and are charting new hybrid urban role within the IPA landscape.

\section{The complexity of IP A planning roles}

Planning reform agendas have rolled out new legislation such as IPA, resulting in policies, processes and practices that have recast the role of the urban planner in novel and increasingly hybrid ways. It is as yet unclear however how planners who inhabit these new blended spaces are reconciling the competing expectations, ambitions and tensions they now face. As Deb, an experienced planning consultant, observed:

Planning is as good as the people who are implementing it...at the end of the day it depends on what pressures are on those people because planners are so stretched....

Two-thirds of the planners interviewed pointed to the continued existence of embedded alliances and advocacy positions between the different sectors, further complicating any newly emerging hybrid role. According to Samantha, a local government planning manager, the culture of the public sector still differs to that of a private enterprise:

Local government has primarily been about regulation so taking risks and exploring alternatives isn't or hasn't been part of the local government culture which is usually about the need to be objective and safe.

A typical view expressed by participants in the public sector was that the advocacy role of a consultant inevitably complicates the agenda of public interest. Kevin, a planner in the public service, referred to these tensions between the different planning spheres:

The private sphere would like us to think that they are being innovative but a lot of what they do is cost reduction. To say the planning consultancy world out there is innovative, well the innovation comes in how they get around the rules and get more gross floor area for their clients - it's very very skewed towards quantity not quality.

The contradictions of working across multiple sectors within the often highly politicised performance-based IPA context were particularly highlighted by Mark, a planner previously employed by a large metropolitan council planner now working as a private consultant. 
During the interview he would unconsciously shift between his different sectoral responsibilities and pressures highlighting the interplay between the different cultural planning contexts. In particular the terms "you" and "we' became fluid collective concepts depending on the context he was describing:

\begin{abstract}
In council you are not given a lot of scope or leeway by your senior people and they are probably a bit cautious to do it because they are playing political games at the same time and they have to be seen to be doing the right thing and they don't want things to blow up in their face An acceptable solution can't blow up in your face[....] So we can argue till the cows come home with council officers about what that performance criteria means because we think our development meets it, but they don't - so what are you going to do? They hold the decision and blackmail you until you come around and change it. So we encourage our clients if you can meet an acceptable solution do it, don't try and be innovative, just get on with it because as soon as you try and put innovation into your developments it is not an acceptable solution so it is going to take a long time to get a decision out.
\end{abstract}

A number of planners pointed out that codes of conduct have been developed by some consultants to help navigate different responsibilities and avoid undue 'conflict of interest' by restricting applications undertaken in areas where a local authority is also a client. However in Queensland such codes are voluntary. A point underscored by Patty, a younger local council planner in relation to the movement of experienced council planners:

Most of the people that were my supervisors and seniors are all in their own private consultancies as planners and before I left development assessment every application was related to a previous work colleague.

Amidst the uncertainty of the IPA planning legislation that is constantly under review, and the outsourcing of key Queensland public planning roles, the lines of professional ethics and conduct seem set to become increasingly unclear.

\title{
Professional dilemmas, uncertain futures
}

What professional challenges and possibilities does this hybrid role entail for urban planning? A recent report by Demos, a British think-tank, prepared in conjunction with the Royal Town Planning Institute (Bradwell et. al., 2007, p.24), sets out a normative vision that emphasises the possibilities for a $21^{\text {st }}$ century hybrid role for planners:

It is time for planners to look outwards and tell a new story about themselves as independent agents of public value working across diverse sectors and interests, to champion inclusive and sustainable development. Only then will collectively produced, democratically legitimate principles be embedded at the heart of the future of our places.

The central message of the report is the need for planners to avoid being caught between the competing ideological silos of public and private interests and instead find a professional role as 'independent arbitrators of global, national, local, individual and future values' (Bradwell et al, p.15). This constitutes a shift to higher levels of autonomy for the planner and the development of governance mechanisms to support this. In the concluding paragraphs entitled Long Live the Planner, the Demos/RTPI report anticipates that the millennium will usher in new age of reign for the autonomous urban planner operating simultaneously across different sectors - a professional 'third space'? 
The professional role of the planner is constructed through conformance to a number of key traits including: specialised knowledge, expertise and skills; independence of authority in transactions with clients; commitment to altruistic public service; and existence of an occupational (professional) association that controls entry to its ranks and establishes standards of professional conduct (Campbell and Marshall, 2005, p.192). A hybrid urban planning role suggests a number of challenges in regard to fulfilling these basic requirements of a profession.

For example, a key professional challenge for a role that occupies a 'third space' is the notion of professional autonomy. A commitment to altruistic public service and limitations around the capacity for planners to serve the 'public interest' and 'public good' within a framework of diversity and difference have already been noted within the Australian context (Fincher, 1998, Sandercock, 1998). The ability for planners to act as independent agents of public value has been questioned within a neoliberalised environment in which the professional planning association has identified rather too closely with the development industry and its political interests, leaving the values of planning largely without the support of professional advocacy' (Gleeson and Low, 2000, p.205).

The narratives of Queensland-based planners suggest that this hybrid role has emerged largely as a result of the impact of ongoing reform agendas on the culture and practice of planning. Planning legislation such as IPA, as many of the planners noted, has created a large windfall for the private sector who now work to support, and arguably drive planning innovation and development in the State. Queensland economist John Quiggin (1998) highlights that when government bodies have been 'commercialised or corporatised in line with the ethos of competition, the application of the public benefit test has been perfunctory, in some cases amounting to little more than a rubber stamp from a consultant' (p.3).

Far from resisting or subverting the dominant neoliberalist paradigm, early findings from the Queensland research suggest that the hybrid role emerges from and is reflective of the contemporary state/ national political and economic agenda (Roy, 2001). One can only speculate what changes will arise as the Queensland/Australian economy responds to the current global financial crisis. In the face of a deepening recession, job cuts have already occurred in the private planning sector in Queensland with further changes predicted to come. Perhaps the opportunities for a hybrid 'after-neoliberalist' state-based role will emerge in the aftermath of this economic stress to enact new and different spatial and social distributional outcomes than those currently framed (McGuirk, 2005). As Lovering (2009, p4) reminds us:

...the era of opportunity-driven pseudo-planning is over. It will not work any more. In the interregnum before a new model for capitalist expansion crystallises out and the economic graphs turn upwards again for another few years, planners will face unfamiliar challenges. The positive side of this is that it will bring new demands for planning to do what it has always presented itself as doing - protecting the needs of ordinary people rather than privileged minorities, the public rather than the private interest, the future rather than the present. Planners will have to take into account new (or rather, old) social forces. And the recession will provide plenty of opportunities for them to focus around and capitalise on. 


\section{Conclusions -Whoever pays the piper plays the tune?}

The breakdown of the post-war welfare model and two decades of neoliberal reform have posed key challenges for urban planners to re-define their role and their professional contribution within an increasingly blurred governance context. From an almost exclusively public service bureaucratic profession in the 1950s, there has been a marked increase in the number of private sector planners working within the contemporary Australian governance setting. More recently planning consultants are now contracted by government to fulfil what were once core public planning roles.

A new breed of urban planner has emerged to navigate a 'third space' both in and between the public, private and third sector realms in a context where Australian planning is increasingly decentred and pulled in often contradictory directions in the pursuit of development (Freestone, 2007). As professionals located within an already complex governance framework, it is assumed that these planners will be both willing and able to balance competing sectoral demands for sustainable outcomes. It is unclear however how this hybrid role might influence planning processes to foster not only economic growth, but also environmental and socially just outcomes for Australian cities and regions.

For hybrid planners located within a contemporary urban environment that has been described as a 'neoliberal dreamworld of consumption, power and property' (Davis and Monk, 2007, p.ix), the task of steering competitive market aspirations to work for the public interest appears to be an increasingly compromised and uncertain endeavour within the flexible, performance-based status quo. A number of planners within the reform context of the IPA in Queensland have claimed that the enactment of multiple planning roles has offered opportunities for unity, collegiality and reflexive learning. Others, however, have pointed to the power dynamics inherent in hybridised roles that emanate largely from a private context and operate within an already hollowed out, under-resourced and short-staffed public realm. In particular, the notion of private consultants operating as independent agents of public value working across diverse sectors and interests, to champion inclusive and sustainable development' (Bradwell et al, 2007, p.24) seems to be a Pandora's Box (AlSayyad 2001) fraught with professional dilemmas.

Thus far, the contemporary dimensions and implications for the planning profession of this evolving hybrid urban planning role, has received little attention within the Australasian planning literature. Urban research, as Davidson and Fincher (1998) observe, might suggest useful ways of understanding these emerging roles, relationships and practices, and the governance spaces they inhabit. In the wake of a global recession it seems timely to re-ignite debate and interest in the professional direction and vision of the emerging role(s) of the Australian urban planner within a pervasive reform agenda that is (once again) under question. A desire to better understand and re-value this professional planning role as a constructive means of furthering sustainable cities and regions within contemporary Australian governance frameworks lies at the heart of this endeavour.

\section{References}

Alexander, I. (2000) The Post-War City, in Hamnett, S. \& Freestone, R. (Eds.) The Australian Metropolis: A Planning History (London: Mansell Publishers).

AlSayyad, N. (ed.) Hybrid Urbanism (Westport, Praeger Publishers).

Baker, D., Sipe, N., \& Gleeson, B. (2006) Performance-based Planning: Perspectives from the United States, Australia and New Zealand, in Journal of Planning Education and Research, 25:396. 
Bhaba, H. (1994) The Location of Culture, (London: Routledge).

Bradwell, P., Johar, I., Maguire, C. and Miner, P. (2007) Future Visions: Propositions for the New Age of Planning (London: Demos).

Brenner, N. (2004) New State Spaces: Urban governance and the Rescaling of Statehood, (Oxford: Oxford University Press).

Campbell, H. and Marshall, R. (2005) The Changing Conception of Professionalism in Planning, Town Planning Review, 76 (2), pp. 191-214.

Commonwealth Housing Commission (1944). Final Report (Canberra: Department of Post-war Reconstruction).

Davidson, G. and Fincher, R. (1998) Urban Studies in Australia: A Road Map and Ways Ahead, Urban Policy and Research, 16 (3), pp.183-197.

Davis, M. and Monk, D. (2007) Evil Paradises: Dreamworlds of Neoliberalism, (London, The New Press).

Dupont, B. (2003) The New Face of Police Governance in Australia, in Journal of Australian Studies, Issue No. 78.

Eckersley, R. (1992) Environmentalism and Political Theory: Towards an Ecocentric Approach, (Albany: State University of New York Press).

Fincher, R. (1998) Planning for Cities of Difference, in Gleeson, B. and Hanley, P. (Eds.) Renewing Australian Planning? New Challenges, New Agendas, (Canberra: Australian National University)

Fogg, A. (2006) Old Wine in New Bottles, The Keeble Lecture 2006, PIA (Qld), Brisbane.

Frawley, K. (1994) Evolving Visions: Environmental Management and Nature Conservation in Australia, in Dovers, S. (Ed.) Australian Environmental History, (Melbourne: Oxford University Press).

Freestone, R. (2007) A History of Planning, in Thompson, S (Ed.) Planning Australia, (New York: Cambridge University Press).

Garnaut, C. (2000) Towards Metropolitan Organization: Town planning and the Garden City Idea, in Hamnett, S. and Freestone, R. (Eds.) The Australian Metropolis: A Planning History, (London: Mansell Publishers).

Gleeson, B. and Low, N. (2000) Australian Urban Planning: New Challenges, New Agendas, (St. Leonards: Allen \& Unwin).

Goss, W. (1992) Queensland -Leading State, State Economic Development Policy, Queensland Government.

Hamnett, S. (2000) The late 1990s: Competitive versus Sustainable cities, in Hamnett, S. and Freestone, R. (Eds.) Australian Metropolis: A Planning History, (Mansell Publishers: London).

Healey, P. (2007) Re-thinking key dimensions of strategic spatial planning: sustainability and complexity, in de Roo, G. and Porter, G. (Eds.) Furzy Planning: The Role of Actors in a Furzy Governance Environment, (Burlington: Ashgate).

Halliday, S. (2004) Findings and recommendations of the National Enquiry into Planning Education and Employment, (Canberra: Planning Institute of Australia).

Howe, E. (1980) Role Choices of Urban Planners, in Journal of the American Planning Association, 46 (4), pp.398-409.

Huxley, M. (2000) Administrative Co-ordination, Urban Management and Strategic planning in the 1970's, in Hamnett, S. \& Freestone, R (Eds.) The Australian Metropolis: A Planning History, (London: Mansell Publishers).

Johnston, R., Gregory, D., Pratt, G., \& Watts, M. (2000) The Dictionary of Human Geography, (Oxford: Blackwell Publishing)

Larner, W. (2005) Neoliberalism in (Regional) Theory and Practice: the Stronger Communities Action Fund in New Zealand, in Geographical Research, 43 (1), pp. 9-18.

Martens, K. (2007) Actors in a Fuzzy Governance Environment, in de Roo, G. \& Porter, G (eds.) Furzy Planning, (Aldershot, Ashgate). 
Massey, D. (1994) Space, Place and Gender, (Cambridge: Polity Press).

McGuirk, P. (2005) Neoliberalist planning? Re-thinking and re-casting Sydney's Metropolitan planning. Geographical Research vol. 43, pp. 59-70.

Minnery, J. (2007) Stars and their Supporting Cast: State, Market and Community as Actors in Urban Governance, in Urban Policy and Research, 25 (3), pp.325-345.

Mitchell, K. (1997) Different Diasporas and the Hype of Hybridity, in Environment and Planning D: Society and Space, 15 (5), pp.533-553.

Powell, T. (2006) Metropolitan Planning: Planning Methods and Institutional Arrangements, Lecture delivered to students at the Department of Planning, University of Melbourne, 11th September.

Queensland Department of Local Government and Planning (2006) Dynamic Planning for a Growing State: A Discussion Paper.

Quiggin, J. (1998), National Competition Policy and Human Services, in Northern Radius 5(3), pp.34.

Rose, G. (1995) The Interstitial Perspective: a review essay on Homi Bhabha's The Location of Culture, in Environment and Planning D: Society and Space, 13, pp. 365-373.

Roy, A. (2001) The Reverse Side of the World: Identity, Space, and Power, in AlSayyad, N. (ed.) Hybrid Urbanism (Westport, Praeger Publishers).

Sandercock, L. (1998) Towards Cosmopolis: Planning for Multicultural Cities (Chichester: Wiley and Sons).

Sandercock, L. (2005) Picking the Paradoxes: A Historical Anatomy of Australian Planning Cultures, in Sanyal, B. (ed.) (2005) Comparative Planning Cultures, (New York: Routledge)

Sanyal, B. (ed.) (2005) Comparative Planning Cultures, (New York: Routledge)

Searle, G. (2004) Planning Discourses and Sydney's Recent Metropolitan Strategies, Urban Policy and Research, 22 (4), pp. 367-391.

Searle, G. (2005) The Redfern-Waterloo Authority: Sydney's Continuing Use of Development Corporations as a Primary Mode of Urban Governance, paper presented at State of Australian Cities (Brisbane: Griffith University).

Wood, P. and Landry, C. (2008). The Intercultural City: Planning for Diversity Advantage, (London: Earthscan).

Wright, B. (2001) Expectations of a Better World - Planning Australian Communities, (Canberra; Royal Australian Planning Institute).

Wypych, S., Sipe, N., and Baker, D. (2005) Performance-based Planning in Queensland, in Australian Planner 42 (3): 26-31.

Yearbury, K. (1998) The Integrated Planning Act: Planning for the New Millenium, in Australian Planner, 35 (4): 197-200. 